\title{
ASO Author Reflections: Does Prompt Breast-Conserving Surgery Matter?
}

\author{
Natalie Hills, BS ${ }^{1}$, Macall Leslie, $\mathbf{B S}^{2}$, Rachel Davis, $\mathbf{B S}^{1}$, Marielle Crowell, $\mathbf{B S}^{1}$, Hiroyasu Kamemyama, $\mathbf{P h D}^{2}$, \\ Hallgeir Rui, $\mathrm{MD}, \mathrm{PhD}^{3}$, Inna Chervoneva, $\mathrm{PhD}^{4}$, William Dooley, $\mathrm{MD}^{5}$, and Takemi Tanaka, $\mathrm{PhD}^{2,5}$ \\ ${ }^{1}$ University of Oklahoma, College of Medicine, Oklahoma City; ${ }^{2}$ Stephenson Cancer Center, Oklahoma City; ${ }^{3}$ Medical \\ College of Wisconsin, Milwaukee; ${ }^{4}$ Thomas Jefferson University Sidney Kimmel Medical College, Philadelphia; \\ ${ }^{5}$ University of Oklahoma, Health Science Center, Oklahoma City
}

\section{PAST}

Time from diagnosis to breast surgery has grown over the past decades in the USA. ${ }^{1,2}$ Studies suggested that delay of surgery is associated with increased mortality risk among early-stage breast cancer patients who were treated with surgery first. ${ }^{3,4}$ This raised the question of whether a prolonged preoperative interval is associated with measurable disease progression.

\section{PRESENT}

This cohort study showed that delay in surgery is associated with disease progression among estrogen receptor (ER)-positive T1N0M0 ductal breast cancer patients who received breast-conserving surgery as their first definitive treatment; however, no such association was observed in ER-negative patients. ${ }^{5}$ This study concluded that avoiding an excessive delay of surgery may reduce preoperative disease progression.

\section{FUTURE}

Given the slow progression of ER-positive compared to ER-negative disease, this observed time-dependent disease progression, specific to T1N0 ER-positive, was

(C) Society of Surgical Oncology 2021

First Received: 5 February 2021

Accepted: 6 February 2021;

Published Online: 5 March 2021

T. Tanaka, PhD

e-mail: takemi-tanaka@ouhsc.edu unanticipated. Extensive translational and clinical studies are needed to understand how "good prognostic" ERpositive tumors progress during a relatively short period between biopsy to surgery. Do tumors begin to become more aggressive around the time they are clinically identified? Does the diagnostic process trigger a change in the biological behavior of ER-positive breast tumors? Despite our improved understanidng of breast cancer, these new and puzzling questions challenge the current paradigms.

DISCLOSURES William Dooley-founding director, Shag Medical LLC-microendoscope company; patent pending on microendoscope for breast ductoscopy.

\section{REFERENCES}

1. Bilimoria KY, Ko CY, Tomlinson JS, et al. Wait times for cancer surgery in the United States: trends and predictors of delays. Ann Surg. 2011;253:779-85.

2. Hulvat M, Sandalow N, Rademaker A, Helenowski I, Hansen NM. Time from diagnosis to definitive operative treatment of operable breast cancer in the era of multimodal imaging. Surgery. 2010;148: 746-50; discussion 750-741.

3. Bleicher RJ, Ruth K, Sigurdson ER, et al. Time to surgery and breast cancer survival in the United States. JAMA Oncol. 2016;2:330-9.

4. Eriksson L, Bergh J, Humphreys K, Wärnberg F, Törnberg S, Czene K. Time from breast cancer diagnosis to therapeutic surgery and breast cancer prognosis: a population-based cohort study. Int $J$ Cancer. 2018;143:1093-104.

5. Hills N, Leslie M, Davis R, et al. Prolonged time from diagnosis to breast conserving surgery is associated with upstaging in hormone receptor positive invasive ductal breast carcinoma. Ann Surg Oncol. 2021. https://doi.org/10.1245/s10434-021-09747-9.

Publisher's Note Springer Nature remains neutral with regard to jurisdictional claims in published maps and institutional affiliations. 